\section{CUTTING-EDGE DIGITAL IMAGING SYSTEMS}

At April's British Dental Conference and Exhibition, the Carestream Dental team demonstrated the power of their cutting-edge practice management and digital imaging systems. The hottest topic was CS Solutions: Carestream Dental's new CAD/CAM Restorations product portfolio, which enables dentists to scan, design, mill and place perfectly crafted restorations in just one appointment.

Popular products included the CS 9300 all-in-one digital imaging solution, which features dedicated panoramic imaging and CBCT technology. Delegates also learned about CS R4 Clinical+ practice management software and Carestream Dental's highly successful eXceed programme - the hallmark of premier customer service.

Carestream Dental supported the BDA's inaugural charity auction by donating a top-of-the-range 1500 intraoral camera, helping to raise much-needed funds for the BDA Benevolent Fund and Bridge2Aid.

www.carestreamdental.co.uk

\section{INEXPENSIVE TOOTH WHITENING KITS}

QuickWhite have launched their new QuickWhite Intenz combined kit, using 6\% hydrogen peroxide for in-surgery and 16\% carbamide syringes for home use, to conform to the new whitening regulations. The in-surgery product comes as $6 \%$ gel syringes or in a powder formula.

The Intenz combined kit is an add-on to QuickWhite's inexpensive Quickwhite carbamide.

Call 01227780009 or visit www.QuickLase.com.

\title{
ENHANCED FORMULAS AND NON-SHREDDING FLOSS
}

Oral-B has enhanced the formula of their innovative Pro-Expert toothpaste even further with the introduction of Oral-B Pro-Expert Gum Protection. In addition to the powerful combination of stabilised stannous fluoride and polyphosphate, Pro-Expert Gum Protection also includes stannous chloride. This ingredient results in 70\% more bioavailable stannous, enhancing the bacteriostatic and bactericidal properties of the formula. Patients are protected against plaque and calculus formation, caries development, dentinal hypersensitivity, staining and oral malodour.

Oral-B now also offers Pro-Expert Premium Pro

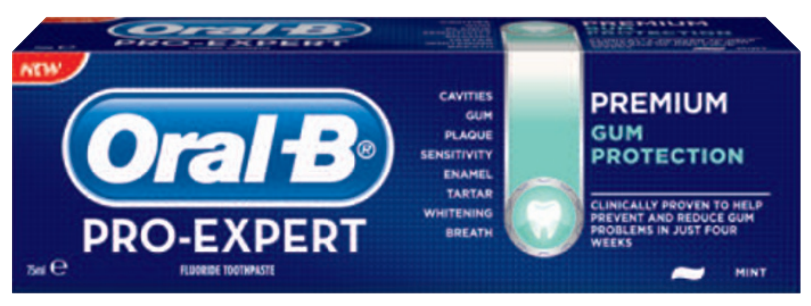

\section{IMPRESSIONS WITHOUT MIXING OR MESS}

3Shape TRIOS is a revolutionary solution in digital impression-taking from Plandent. No more mixing or mess with conventional impression materials and significantly fewer re-takes.

3Shape TRIOS is a no-spray solution - spraying is technique demanding, can ruin scan accuracy, is uncomfortable for patients and prolongs chairtime - therefore no-spray is the best option. 3Shape's technology captures more than 3,000 2D images per second - 100 times faster than conventional video cameras. There's no need to hold the
Flex, a manual toothbrush with flexible 'wings' which allow it to adjust to the unique contours of an individual's teeth and gums. These wings are flexible but firm enough to facilitate a 35\% greater plaque reduction at the gingival margin versus an ADA standard brush.

In complement to their other products, Oral-B has introduced Pro-Expert Premium Floss which has a monofilament strand that is non-shredding and slips easily between the tightest of contacts.

Delegates at the British Dental Conference and Exhibition were lucky enough to receive samples of new Oral-B products in their delegate bags.

\section{HELP YOUR PATIENTS ENJOY LIFE WITH PARTIAL DENTURES}

The new Poligrip for Partials range is specially designed for patients with partial dentures to use as part of their daily oral care routine, to help protect their denture and their remaining natural teeth.

Poligrip for Partials Clean \& Protect denture cleansing tablets are proven to help reduce plaque and stain build-up (when used as directed); are suitable for use with metal clasps; are non-corrosive and non-abrasive; and kill 99.9\% of odour-causing bacteria.

The Poligrip for Partials Seal ct Protect denture fixative cream helps stabilise partial dentures and reduces movement on the gum and against neighbouring teeth. The cream also helps seal out food particles to reduce gum irritation.

For more information on the Poligrip range, visit www.poligrip.co.uk. Poligrip Partial Denture Starter Kits can be requested at www. gsk-dentalprofessionals. co.uk or by calling 0845 6000441.

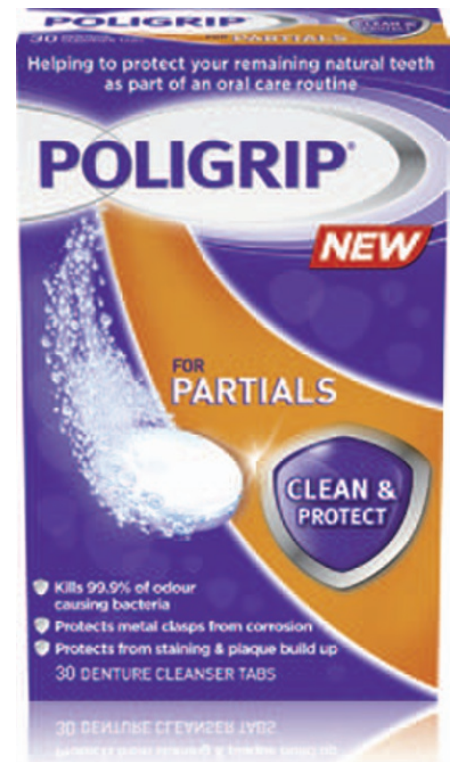

